\title{
Anelamento e incisão anelar em fruteiras de caroço
}

\author{
Girdling and ringing of stone fruit trees
}

IvarAntonio Sartori $^{1}$ Luciano Larruscahim Hamilton Ilha ${ }^{2}$

\section{- REVISÃO BIBLIOGRÁFICA -}

\section{RESUMO}

O cultivo de pessegueiros é uma atividade de grande importância econômica no Sul do Brasil, e o Estado do Rio Grande do Sul se destaca como o maior produtor brasileiro. Grande parte dos pomares se encontram na Metade Sul do Estado. Um dos principais problemas da cultura para o consumo de frutas in natura é o tamanho reduzido das mesmas e a produção concentrada, que dificultam a comercialização. $O$ anelamento e/ou a incisão anelar de ramos pode ser usada, com o intuito de aumentar a massa média das frutas e antecipar o período de colheita. Esta revisão busca encontrar dados referentes à época de execução, cuidados necessários, problemas associados e aspectos fisiológicos do anelamento e incisão anelar de ramos em fruteiras de caroço, principalmente pêssegos, ameixas e nectarinas de maior expressão comercial no sul do Brasil. $O$ anelamento e/ou a incisão anelar torna-se uma prática útil para melhorar a qualidade da fruta e antecipar a colheita de cultivares de maturação precoce. Contudo, faz-se necessário a realização de estudos locais para as diferentes espécies $e$ cultivares. A prática da incisão anelar é mais recomendada pela facilidade de execução e com resposta semelhante ao anelamento. A época mais indicada para a realização da incisão anelar é na fase de lignificação do endocarpo. Recomendações devem ser específicas para cada situação e o anelamento, em conjunto com outras práticas, poderá promover a antecipação da maturação e contribuir para melhorar a qualidade organoléptica das frutas.

Palavras-chave: Prunus persica, antecipação de colheita, qualidade de fruto.

\begin{abstract}
Growing peaches is of high economic importance in South of Brazil and the State of Rio Grande do Sul is the biggest brazilian producer. Largest part of the orchards are located in the Southern half. One of the main problems of peach production for fresh consumption in this area is the reduced size of the fruits. Another problem is the short harvesting window, which brings difficulties to commercialization. Girdling and/or ringing of branches might be used to increase fruti size and eventually extend the harvesting period. The present review intends to gather data regarding the most adequate period to apply treatments, to understand the physiological aspects and problems associated with these practices on stone fruit trees. Girdling and ringing of stone fruit trees might be useful to improve quality and anticipate harvest period of early ripening cultivars. It is necessary to conduct local studies for different species and cultivars. Recomendations should be specific for each situation and girdling and ringing together with other pratices to induce early ripening might help to anticipate harvest and ameliorate organoleptic of the fruit.
\end{abstract}

Key words: Prunus persica, harvest anticipation, fruit quality.

\section{INTRODUÇÃO}

A produção mundial de pêssegos e nectarinas no ano de 2003 foi da ordem de 14 milhões

${ }^{1}$ Engenheiro Agrônomo, MSc, Fitotecnia, Fruticultura pela Faculdade de Agronomia, Universidade Federal do Rio Grande do Sul, Estudante de Doutorado, Rua Dario Cardoso, 67, Bairro Ipanema, 91770-260, Brasil. E-mail: ivarsartori@yahoo.com.br. Autor para correspondência.

${ }^{2}$ Engenheiro Agrônomo, MSc, Fitotecnia, Fruticultura pela Faculdade de Agronomia, Universidade Federal do Rio Grande do Sul, Associação Riograndense de Empreendimentos de Assistência Técnica e Extensão Rural, RS, Escritório Municipal de Caxias do Sul, Rua Jacob Luchesi, 3181, Bairro Santa Lúcia, 95030-000, Brasil. Fone: (0xx)54 201 1208. E-mail: lucianoilha@hotmail.com. 
de toneladas. O Brasil aparece como o $13^{\circ}$ produtor mundial de pêssego com 184 mil toneladas (FAO, 2003), sendo que o Rio Grande do Sul é o maior produtor nacional, com aproximadamente 108 mil toneladas de pêssegos em uma área cultivada de 13.761ha. Desse total, 8.723ha foram destinados à indústria e 5.038ha para o mercado de fruta de mesa (EMATER, 2004). Os demais Estados brasileiros que se sobressaem na produção de pêssegos são: São Paulo, Paraná e Minas Gerais (MARODIN \& SARTORI, 2000).

A produção de frutas com elevado padrão de qualidade, aparência e sabor, são características importantes a serem observadas em frutas para o consumo "in natura” (ILHA, 1997). A utilização de técnicas como a incisão anelar em ramos, pode influenciar positivamente estas características, principalmente em cultivares precoces (ALMELA et al., 1995; AGUSTÍ et al., 1996 e 1998).

Frutas de pequeno tamanho e a baixa produção são problemas comuns na exploração comercial de frutíferas de caroço, quando se utilizam cultivares de maturação precoce. Essas características são toleradas pelos produtores porque os preços obtidos para tais frutas são inicialmente elevados, mas o mercado, por ser muito dinâmico, pode oscilar rapidamente (DAY \& DEJONG, 1990). Além do pequeno tamanho, pêssegos, nectarinas e ameixas de maturação precoce freqüentemente apresentam outros defeitos qualitativos que reduzem o valor comercial, tais como: sabor, coloração e distúrbios fisiológicos (FERNANDEZ-ESCOBAR et al., 1987).

$\mathrm{O}$ anelamento dos ramos é simplesmente a remoção de um anel completo da casca (epiderme, capas subepidérmicas e floema) do tronco ou de ramos da árvore, bloqueando temporariamente o movimento da seiva elaborada das folhas para a raiz. Isso resulta em um acúmulo de carboidratos e fitohormônios acima da região anelada (SALISBURY \& ROSS, 1996). O floema é muito rico em substâncias orgânicas sintetizadas pelas folhas, sendo imprescindível para o desenvolvimento de órgãos da planta como a fruta (LIPE, 1988; AGUSTÍ et al., 1996, 1998 e 1999). O anelamento é feito com canivetes de lâminas duplas, espaçadas de 2 a $5 \mathrm{~mm}$ de espessura. Para pessegueiros, a largura do anelamento é, geralmente, de 3,2 a 4,8mm, variando de acordo com a idade e porte da planta (LIPE, 1988). Este pode ser realizado nos ramos principais ou no tronco. Quando realizado nos ramos principais e mais próximos da parte aérea, a distribuição dos fotoassimilados para o fruto é maior, com menor dispersão para ramos e folhas adjacentes (AGUSTÍ et al., 1999). O importante é que uma secção completa de casca ao redor do tronco ou ramo seja removida, pois, se alguma porção de casca permanecer, o fluxo de seiva para as raízes continuará ocorrendo e a resposta ao anelamento não será satisfatória (LARUE \& JOHNSON, 1988).

A incisão anelar consiste na execução de um corte completo de aproximadamente $1 \mathrm{~mm}$ de espessura no córtex dos ramos principais, sem afetar o xilema e sem a retirada da casca. A incisão anelar é feita com auxílio de uma tesoura de lâmina curva (ALMELA et al. 1995; AGUSTÍ et al., 1996), e é de rápida execução e menos agressiva do que anelamento, sendo que a cicatrização ocorre entre 10 a 15 dias. A ausência de exsudações de goma evidencia a facilidade de união dos tecidos. Esta prática não reduz o vigor e a produção da planta nos anos posteriores, podendo ser repetida em anos consecutivos (ALMELA et al., 1995; AGUSTÍ et al., 1996, 1998 e 1999; SARTORI et al., 2003 a,b).

Estudos comparativos entre o anelamento e a incisão anelar foram executados em diversas frutíferas de caroço, com resultados similares, levando os autores a propor a incisão anelar como uma modalidade de anelamento mais vantajosa devido à praticidade e o baixo custo de execução (ALIAGA et al., 1990; ALMELA et al., 1995; JUAN et al., 1995 e 1996; AGUSTÍ et al., 1996, 1998 e 1999).

O anelamento é uma prática antiga, que tem sido utilizada em várias espécies, com inúmeras finalidades. Esse, em espécies frutíferas, estimula a floração (PÉREZ \& RODRIGUEZ, 1987), melhora a fixação das frutas (AGUSTÍ et al., 1996 e 1999), aumenta a produção (ALMELA et al., 1995; AGUSTÍ et al., 1996), o tamanho das frutas e melhora características de qualidade como a cor, teor de açúcares e acidez das frutas (ALIAGA et al., 1990; ALMELA et al., 1995; AGUSTÍ et al., 1996, 1998 e 1999). Também adianta a maturação (SARTORI et al., 2003 a,b) e reduz o comprimento das brotações e o crescimento do câmbio (PÉREZ \& RODRIGUEZ, 1987).

Esta revisão busca encontrar dados referentes à época de execução, cuidados necessários, problemas associados e aspectos fisiológicos do anelamento e incisão anelar de ramos em frutas de caroço, principalmente pêssegos, ameixa e nectarinas de maior expressão comercial no sul do Brasil, com intuito da antecipação da colheita e melhoria das qualidades físico-químicas das frutas.

\section{Problemas associados ao anelamento}

A capacidade de cicatrização da região anelada não é apenas dependente da espécie (NOEL, 1970), mas também da cultivar (FERNANDEZESCOBAR et al., 1987). Desta forma, para que o 
anelamento possa ser recomendado com segurança, são necessários estudos específicos em nível de cultivar.

O aumento da incidência de distúrbios que reduzem a qualidade das frutas é um dos principais efeitos indesejáveis do anelamento. A incidência de caroço partido é um dos efeitos mais preocupantes. $\mathrm{O}$ anelamento aumenta a percentagem de frutas com caroço partido, principalmente em cultivares suscetíveis (LARUE \& JOHNSON, 1988) e a lanosidade (DE VILLIERS et al., 1990). Este distúrbio se manifesta no período de armazenamento refrigerado e altera a qualidade interna da fruta (LARUE \& JOHNSON, 1988).

A habilidade de cicatrização da lesão produzida pelo anelamento varia conforme a espécie e a variedade. Esta prática é pouco indicada para frutas de caroço devido à deficiente cicatrização (NOEL, 1970). No entanto, estudos mais recentes indicam efeitos positivos do anelamento sobre a massa e precocidade das frutas em pessegueiros e nectarineiras (ANDREWS et al., 1978; FERNANDEZ-ESCOBAR et al., 1987; PÉREZ \& RODRIGUEZ, 1987; DAY \& DEJONG, 1990; (ALIAGA et al., 1990; ALMELA et al., 1995; AGUSTÍ et al., 1996, 1998 e 1999; SARTORI et al., 2003 a,b) embora alguma variabilidade, tanto nos efeitos positivos como negativos, tenham sido encontradas entre cultivares.

\section{Cuidados necessários}

Até a região anelada estar cicatrizada, as plantas são facilmente danificadas e, se o pomar não receber cuidados adequados, a planta ou os ramos podem morrer. Anelamento muito profundo, abaixo da faixa do câmbio, pode causar danos. Algumas variedades precoces respondem bem ao anelamento, enquanto outras mostram efeitos negativos. Esta prática deve, portanto, ser utilizada com cautela e sob circunstâncias em que seus efeitos são bem conhecidos. Cultivares de meia estação e tardias tipicamente não são aneladas, pois as vantagens econômicas não são grandes, nesta situação (LARUE \& JOHNSON, 1988). Apesar dos efeitos positivos, o anelamento pode prejudicar as plantas e danos permanentes podem ocorrer caso não ocorra cicatrização adequada da região anelada (FERNANDEZ-ESCOBAR et al., 1987). Muitos pesquisadores têm observado uma diminuição do vigor da planta pelo efeito do anelamento (ANDREWS et al., 1978; DANN et al., 1984; PÉREZ \& RODRIGUEZ, 1987), com diminuição do crescimento vegetativo. Cortes muito profundos, que ultrapassem a faixa do câmbio e atingem o xilema, abaixo da casca, podem causar extravasamento de seiva. O tecido xilemático transporta água e nutrientes das raízes para a parte superior da planta. O anelamento muito profundo interrompe este fluxo ascendente e, temporariamente, interrompe a porção acima da região anelada de água e nutrientes (LARUE \& JOHNSON, 1988; SARTORI et al., 2003 a).

Não é necessário aplicar medidas de proteção da região anelada, pois ela autocicatrizará. Freqüentemente ocorre secreção de goma da região anelada. Tecido de cicatrização rapidamente forma-se em cada lado do corte e, se realizado corretamente, o anelamento estará quase completamente cicatrizado na época da maturação dos frutos (LARUE \& JOHNSON, 1988; AGUSTÍ et al., 1996).

Época de realização

Frutas de caroço seguem um modelo de crescimento que é representado por uma curva duplasigmóide, com três estádios: uma fase inicial de crescimento exponencial (Estádio I), uma fase lag (Estádio II) e uma segunda fase exponencial (Estádio III) (CRANE, 1969). O anelamento na época do início do endurecimento do caroço (endocarpo), no começo do estádio II, é uma prática estabelecida para aumentar o tamanho dos frutos em pessegueiros (ANDREWS et al. 1978; FERNADEZ-ESCOBAR et al., 1987). No entanto, a data deste estádio de desenvolvimento é difícil de predizer pois, mesmo para uma mesma cultivar, o começo do estádio II varia de ano para ano devido a diferenças nas respostas ao frio, data da floração e temperaturas ocorrentes após a floração (DAY \& DEJONG, 1990). O tamanho da semente tem sido um método bastante utilizado para determinar o momento ótimo para a realização do anelamento.

A época mais adequada de aplicação da incisão anelar é aquela em que a fruta se encontra no estádio de "endurecimento do caroço”. Este período coincide com um momento em que o fruto reduz seu crescimento, que antecede ao crescimento rápido da polpa. Este intervalo corresponde a 12 a 15 dias, durante o endurecimento do endocarpo (AGUSTÍ et al., 1996).

Resultados obtidos com o anelamento e incisão anelar

Os fatores que afetam os resultados obtidos com o anelamento são muitos. Além da espécie e cultivar, as respostas ao anelamento são influenciadas pela largura de anelamento, pela época de realização e pelas condições ambientais e de manejo do pomar.

A influência da largura de anelamento sobre o tamanho de pêssegos da cultivar Sprigtime, foram determinadas por ocasião da colheita. $\mathrm{O}$ anelamento 
foi realizado no tronco das plantas e, além da largura $(0,5$ e $10 \mathrm{~mm})$, avaliou-se o efeito de época de anelamento (0, 15 e 21 dias após a plena floração), sendo que a diferença entre o efeito dessas diferentes épocas não foi significativo. Os resultados obtidos neste experimento mostram que, com aumento na largura de anelamento, aumentam o diâmetro médio das frutas e a percentagem de frutas nas classes de maior valor comercial. Os mesmos autores também demonstraram que grandes larguras de anelamento $(10 \mathrm{~mm})$ podem resultar em cicatrização deficiente da região anelada. Para três cultivares de nectarineira (Maybelle, Armking 2 e Armking 3) e uma de pessegueiro (Armgold), verificou-se que o anelamento, realizado nas pernadas principais da planta, 30 dias após a plena floração, resultou em deficiente cicatrização da região anelada, quando a largura de anelamento foi de $10 \mathrm{~mm}$ (FERNANDEZ-ESCOBAR et al., 1987).

Apesar de muitos trabalhos terem comprovado que a largura de anelamento é um fator importante no anelamento de frutíferas de caroço, resultados experimentais indicam que o efeito sobre o tamanho do fruto foi similar, tanto com o anelamento quanto com a incisão anelar. A incisão anelar mostrou efeito positivo em pessegueiro, ameixeira e outras espécies, com menor agressão à planta e maior facilidade de execução que o anelamento. Na Espanha, estudou-se o anelamento e a incisão anelar dos ramos das plantas. A incisão anelar foi a mais viável por ser de rápida execução e de menor agressividade que o anelamento. A ferida que se produz é de menor intensidade, o que facilita a cicatrização. Também em trabalho com plantas aneladas, o período climatério iniciava antes das plantas testemunha. A produção de ACC (amilociclopropano), ACC-oxidase e etileno foi notável para a cultivar Flordastar em plantas aneladas. Além do mais, a incisão anelar aumentou o teor de sólidos solúveis totais e diminui a firmeza de polpa e a porcentagem de caroço partido não foi afetada (ALMELA et al., 1995; AGUSTÍ et al., 1996 e 1998).

$\mathrm{O}$ anelamento imediatamente antes do endurecimento do caroço proporcionou os melhores resultados em nectarineiras 'Mayfire' podendo-se concluir que, nesta época, o anelamento promoveu um aumento de $22,5 \%$ na massa média das frutas e de 42\% na concentração de sólidos solúveis totais nas frutas maduras (DAY \& DEJONG 1990). Resultados semelhantes foram encontrados para a cultivar Flordaprince com aumento de massa da fruta e maior percentagem de frutas comercializáveis (ALLAN et al., 1991). Já em um sistema intensivo de produção, no México, com anelamento antes da plena floração e 15 dias antes da maturação das frutas de pêssegos, que em qualquer das épocas da realização, propiciou a concentração da maturação no início do período de colheita, foi semelhante (PÉREZ \& RODRIGUEZ, 1987).

A incidência de distúrbios fisiológicos nas frutas geralmente aumenta com o anelamento quando realizado sete semanas depois da plena floração. Os efeitos do anelamento de pessegueiros 'Culemborg' como caroço partido e lanosidade aumentam a incidência destes e diminuem o valor comercial das frutas. Já para o tamanho das frutas maduras e seu teor de sólidos solúveis totais, aumentou com a prática do anelamento (DE VILLIERS et al., 1990).

O anelamento do tronco com a retirada de um anel de casca de $4 \mathrm{~mm}$ de largura ao redor do tronco principal a $30 \mathrm{~cm}$ do solo, em ameixeira japonesa (Prunus salicina Lindley) cv. Amarelinha, aos 43 dias após a plena floração, antecipou a maturação e a colheita das frutas, aumentou a percentagem da produção colhida na primeira colheita. $\mathrm{O}$ anelamento do tronco, no ano de sua realização, diminuiu o vigor e o crescimento, mas não provocou injúrias às plantas, sendo que, no inverno seguinte à aplicação dos tratamentos, a área anelada estava completamente cicatrizada. No segundo ano após a aplicação dos tratamentos, as plantas aneladas no ano anterior apresentavam menor incremento na área de secção transversal do tronco, mas não foram observados efeitos dos tratamentos sobre a produção e massa média das frutas (ILHA, 1997). Em trabalhos com uso de auxinas e incisão anelar nas cultivares de pessegueiro 'Diamante' e 'Sentinela', determinou-se que incisão anelar associada com aplicações de auxinas de síntese antecipou a colheita de frutos em torno, de 10 a 15 dias e proporcionou incrementos de ganho de massa média das frutas (SARTORI et al., 2003 a,b).

\section{Aspectos fisiológicos}

O anelamento causa uma interrupção temporária no fluxo descendente de carboidratos para as raízes, de procedência das folhas, onde se acredita que esses açúcares e amidos são direcionados para os frutos como uma fonte de energia para o crescimento e desenvolvimento (LARUE \& JOHNSON, 1988). Também o anealmento altera a distribuição de fotoassimilados, fazendo com que os ramos anelados suportem um incremento no crescimento dos frutos com diminuição do crescimento vegetativo (CUTTING \& LYNE, 1993).

Os efeitos do anelamento não podem ser explicados somente em função da distribuição dos carboidratos, pois já foram detectadas alterações no balanço endógeno de auxinas (DANN et al., 1985), 
giberelinas e citocininas (CUTTING \& LYNE, 1993) e elementos minerais (DAY \& DEJONG, 1990; SCHECHTER et al., 1994). O anelamento reduz a habilidade das brotações em competir com os frutos por assimilados (DANN et al., 1984). Os autores sugerem que o anelamento inicialmente provoca acúmulo de substâncias reguladoras de crescimento, produzidas acima da região anelada. O reduzido fluxo dessas substâncias para as raízes eventualmente poderia resultar em menores níveis de substâncias reguladoras de crescimento produzidas pelas raízes, o que causaria efeitos em toda a planta. O anelamento provoca um aumento na concentração de auxina acima da região anelada e uma diminuição abaixo dessa região. Porém, em poucos dias, a concentração de auxina acima da região anelada volta aos níveis normais. A comprovada alteração no balanço endógeno de auxinas é considerada como uma das explicações mais importantes para o aumento do tamanho do fruto provocado pelo anelamento. Assim, a época de realização do anelamento, que é considerada um fator crítico, deve ser precisa e coincidir com a maior sensibilidade da planta e dos frutos, a altas concentrações destas substâncias( DANN et al., 1985).

O anelamento em pessegueiros, realizado no início do estádio II de crescimento do fruto, diminuiu significativamente a concentração de citocininas e giberelinas na seiva do xilema de ramos situados acima da região anelada (CUTTING \& LYNE, 1993). Uma das hipóteses para explicar as causas dessa alteração no balanço de citocininas e giberelinas é a menor produção de fitohormônios pelas raízes, proposta por (DANN et al., 1984). A concentração de elementos minerais nas folhas geralmente diminui com o anelamento e, provavelmente, também contribui para a redução do crescimento vegetativo (DAY \& DEJONG, 1990).

A habilidade de pessegueiros cv. Suncrest com 3 anos de idade de mobilizar suas reservas de carboidratos em resposta ao anelamento, ocasionou decréscimo na concentração de carboidratos não estruturais insolúveis nas raízes e na casca do portaenxerto, abaixo da região anelada. As concentrações de carboidratos não estruturais solúveis nos órgãos localizados tanto acima, quanto abaixo do anelamento não foram significativamente afetados. Diante desses resultados, os autores concluíram que o anelamento causou mobilização de reservas de carboidratos, abaixo da região anelada, proporcionando a manutenção das concentrações de açúcar, em todos os tecidos da planta, no mesmo nível que em plantas não aneladas (JORDAN \& HABIB, 1996). Quando o anelamento foi realizado por duas semanas em diferentes estádios fenológicos em pessegueiro (Prunus persica L. Bastch) com três anos de idade, na França, este diminui o transporte de nitrogênio de acordo com o estádio fenológico em $19 \%$. Por outro lado, o anelamento não afetou a proporção de nitrogênio acima da área anelada ( JORDAN et al., 1998). Percebe-se que ainda existem muitos aspectos que precisam ser esclarecidos para que os mecanismos fisiológicos envolvidos na reação das plantas ao anelamento possam ser mais bem compreendidos.

\section{CONSIDERAÇÕES FINAIS}

O anelamento é uma prática útil para melhorar a qualidade e antecipação da colheita de fruteiras de caroço, principalmente de maturação precoce. É fundamental a realização de estudos para cada espécie e cultivar para se determinar os fatores que afetam as respostas, tanto positivas como negativas. A prática da incisão anelar torna-se mais recomendada pela facilidade de execução. Esta requer um treinamento do aplicador no momento de executar a incisão anelar para que não corte o xilema, evitando o extravasamento de seiva bruta, sendo que a época mais recomendada para a realização da incisão anelar é na fase de lignificação do endocarpo. Associado à prática do raleio manual, a incisão anelar poderá incrementar ainda mais o tamanho final dos frutos, especialmente em cultivares de maturação precoce, as quais comumente apresentam frutos com tamanho insatisfatório, mesmo com raleio adequado.

Ao contrário de outras práticas que visam antecipar a colheita dos frutos, como a aplicação de produtos químicos para antecipar a brotação e o florescimento, o anelamento não antecipa a época de floração, pois é realizado posteriormente e, desta forma, não aumenta os riscos de prejuízos devido às geadas tardias. Além disso, não pode ser descartada a possibilidade da utilização do anelamento em conjunto com a aplicação de fitorreguladores que promovam a antecipação da maturação, visando obter uma colheita antecipada de fruta.

\section{REFERÊNCIAS BIBLIOGRÁFICAS}

AGUSTÍ, M. et al. Estímulo del desarrollo de los frutos de hueso. Valencia : Generalitat Valenciana, 1996. 78p.

AGUSTÍ, M. et al. Effects of ringing branches on fruit size and maturity of peach and nectarine cultivars. Journal of Horticultural Science \& Biotechnology, Valência, v.73, n.4, p.537-540, 1998.

AGUSTÍ, M. et al. Ameixa, cereja, damasco e pêssego: técnicas avançadas de desbaste, anelamento e fitorreguladores na produção de frutos de primeira qualidade. Porto Alegre : Cinco Continentes, 1999. 91p. 
ALIAGA, J.R. et al. A new method of ringing to improve the fruit size in peaches (Prunus persica (L.) Batsch). In: INTERNATIONAL HORTICULTURAL CONGRESS, 23., 1990, Florence. Anais... Florência: Itália, 1990. p.3281. Abstract.

ALMELA, V. et al. La incisión anular como técnica de estímulo del desarrollo de los frutos de hueso. Fruticultura Profesional, Barcelona, n.69, p.16-26, 1995.

ALLAN, P. et al. Effects of girdling time on growth, yield, and fruit maturity of the low chill peach cultivar flordaprince. Australian Journal of Experimental Agriculture, Melbourne, v.33, n.6, p.781-785, 1991

ANDREWS, C.P. et al. Response of peach and nectarine cultivars to girdling. Proceedings of the Florida State Horticultural Society, Taliahassee, v.91, p.175-177, 1978.

CRANE, J.C. The role of hormones in fruit set and development. Hortscience, Alexandria, v.4, n.2, p.108-lll, 1969.

CUTTING, J.G.M.; LYNE, M.C. Girdling and the reduction in shoot xylem sap concentrations of cytokinins and gibberellins in peach. Journal of Horticultural Science, Ashford, v.68, n.4, p.619-626, 1993.

DANN, I.R. et al. Short term changes in cambial growth and endogenous IAA concentrations in reiation to phloem girdling of peach, Prunus persica (L.) Batsch. Australian Journal of Plant Physiology, Melbourne, v.12, p.395-402, 1985.

DANN, I.R. et al. Effects of limb girdling on growth and development of competing fruit and vegetative tissues of peach trees. Australian Journal of Plant Physiology, Melbourne, v.11, p.49-58, 1984

DAY, K.R.; DEJONG, T.M. Girdling of early season 'Mayfire' nectarine trees. Journal of Horticultural Science, Ashford, v.65, n.5, p.529-534, 1990.

DE VILLIERS, H. et al. The effect of girdling on fruit growth and internal quality of Culemborg peach. Journal of Horticultural Science, Ashford, v.65, n.2, p.151-155, 1990.

EMATER. Levantamento da fruticultura comercial do Rio Grande do Sul - 2003/2004. EMATER. Rio Grande do Sul/ASCAR, Porto Alegre, 2004. 81p. il.

FAO. FAOSTAT. . On line. Disponível na internet. http:// www. fao.org.com/. Capturado em 06 maio 2003

FERNANDEZ-ESCOBAR, R. et al. Girdling as a means of increasing fruit size and earliness in peach and nectarine cultivars. Journal of Horticultural Science, Ashford, v.62, n.4, p.463-468, 1987.

ILHA, L.L.H. Intensidades de raleio manual e anelamento do tronco em ameixeira japonesa (Prunus salicina Lindley) cultivar Amarelinha. 1997. $124 \mathrm{f}$. Dissertação (Mestrado em Fitotecnia) - Programa de Pós- graduação em Agronomia, Universidade Federal do Rio Grande do Sul.

JORDAN, M.O.; HABIB, R. Mobilizabie carbon reserves in young peach trees as evidenced by trunk girdling experiments. Journal of Experimental Botany, Oxford, v.47, n.294, p.179-87, 1996

JORDAN, M.O. et al. Uptake and allocation of nitrogem in young peach trees as affected by the amount of photosynthates avalilable in roots. Journal of Plant Nutrition, Avignon, v.21, n.11, p.2441-2454, 1998.

JUAN, M. et al. EI rayado de ramas como técnica para mejorar la calidad de los frutos de hueso. Valencia : Generalitat Valenciana. Conselleria de agricultura y medio ambiente, 1995. 17p.

JUAN, M. et al. El rayado de ramas como técnica para aumentar la calidad de los frutos en el cerezo (Prunus avium L.). Agrícola Vergel, Valencia, v.171, p.130-134, 1996.

LARUE, J.M.; JOHNSON, S. Girdling fresh shipping peach and nectarine trees, California. In: CHILDERS, N.F.; SHERMAN, W.B. The peach: world cultivars to marketing. 4.ed. Gainesville : Horticultural Publications, 1988. p.540-545.

LIPE, J.A. Peach tree girdling. In: CHILDERS, N.F.; SHERMAN, W.B. The peach: world cultivars to marketing. 4.ed. Gainesville: Horticultural Publications, 1988. p.546-548.

MARODIN, G.A.B.; SARTORI, A.S. Situação das frutas de caroço no Brasil e no mundo. In: SIMPÓSIO INTERNACIONAL DE FRUTAS DE CAROÇO - PESSEGOS, NECTARINAS E AMEIXAS, 1., 2000, Porto Alegre. Anais... Porto Alegre : UFRGS-DHS, 2000. p.7-16.

NOEL, A.R.A. The girdied tree. The Botanical Review, New York, v.36, n.2, p.162-195, 1970.

PÉREZ, B.H.; RQDRIGUEZ, A.J. Efecto deI aniliado en ei rendimiento y calidad dei fruto de árboles de durazno (Prunus persica L.) bajo un sistema de producción intensiva. Agrociencia, Chapingo, n.68, p.63-73, 1987.

SALISBURY, F.B.; ROSS, C.W. Fisiologia vegetal. México, D.F. : Grupo Editorial Iberoamérica, 1996. 759p.

SARTORI, I.A. et al. Aplicação de auxinas e incisão anelar em pessegueiros da cv. Sentinela. Ciência Rural, Santa Maria, v.33, n.2, p.247-253, $2003 a$.

SARTORI, I. A. et al. Aplicação de auxinas e incisão anelar de ramos em pessegueiros cv. Diamante. Revista Brasileira de Fruticultura, Jaboticabal, v.25, n.1, p.14, $2003 b$.

SCHECHTER, I. et al. Apple fruit removal and limb girdling affect fruit and leaf characteristics. Journal of American Society for Horticultural Science, Alexandria, v.119, n.2, p.157-162, 1994 